\title{
Neither molecular nor morphological data have all the answers; with an example from Macrobrachium (Decapoda: Palaemonidae) from Australia
}

\author{
TIMOTHY J. PAGE \& JANE M. HUGHES \\ Australian Rivers Institute, Griffith University, Nathan, Queensland, 4111, Australia.E-mail: penguintim@hotmail.com
}

Much controversy still seems to surround the role of molecular data in general, and DNA barcoding in particular, within the taxonomic community. This has lead to numerous "call and response" pairs of papers, most recently Ebach (2011) and Mitchell (2011), but preceded by many other pairs, such as Packer et al. (2009) and Hołyński (2010). There have been numerous calls for a more "integrative" approach to taxonomy (Mitchell 2011; Stevens et al. 2011), which itself has generated point and counterpoint papers (Dayrat 2005; Valdecasas et al. 2008). This of course is how science progresses (although Max Planck suggested that science advances “one funeral at a time”, en.wikiquote.org/wiki/Max_Planck, accessed 20 March 2011).

If one looks carefully at many of these papers, there is almost always an acknowledgement of the utility of the "other" type of data, such as "We emphasize that DNA barcoding is not a substitute for conventional taxonomic approaches" (Costa et al. 2007) or "Sometimes molecular analysis may be the most convenient way to clarify the taxonomical assignments between sexes, developmental stages, castes etc.” (Hołyński 2010). Surely, eventually a point is reached when, to paraphrase U2's Bono, "There's been a lot of talk about this, maybe too much talk" (Under a Blood Red Sky, 1983), and perhaps we should all just get on with it.

It seems pretty obvious to us that both types of data are extremely useful, have their own strengths, weaknesses and purviews (with some overlap), and one would be foolish to ignore either of them out of hand. Both DNA barcoding and morphological descriptions are often the tip of the scientific iceberg and a starting point for further scientific analyses. Neither morphological characters nor DNA sequences fully define a living, breathing biological organism, any more than your passport photo fully reflects you.

\section{An example from freshwater prawns}

We think that these sorts of discussions are best carried out with reference to real data rather than as philosophical debates, and so we present some new data on Australian freshwater river prawns Macrobrachium (Palaemonidae) to show the utility and futility of both molecular and morphological data. In the spirit of full disclosure, we need to admit that we are both evolutionary biologists who primarily use molecular data, but with an interest in taxonomy, if perhaps no great skills in it; but we know people who have. We were sent an unidentified juvenile specimen (Queensland Museum accession number W29088) from the Northern Territory, Australia, by Dave Wilson of Aquagreen. Juvenile Macrobrachium can be notoriously difficult to identify accurately to species using traditional morphological methods (Holthuis 1950) because many of the commonly used taxonomic characters are conserved between species in juveniles, and because most morphological identification requires adult males (Short 2004). We asked Dr John Short of BioAccess Australia to examine the morphology of this specimen for us. He determined that it was an undeveloped, sexually immature male that could not be distinguished from M. equidens (Dana) at that stage of development, and would also be hard for many people to distinguish from M. novaehollandiae (De Man) (J. Short, pers. comm.).

At this stage, we were pretty confident that we could identify it using fairly prosaic "DNA barcode"-type methods (Costa et al. 2007). This was because this genus is well known in Australia, both morphologically, thanks to a comprehensive taxonomic revision by Short (2004), as well as molecularly, as all 13 species known to occur in Australia have been sequenced (many in Murphy and Austin 2004). Therefore matching our new sequences from an unknown juvenile specimen to existing sequences from identified specimens should have been straightforward.

We followed a well-worn "pedestrian" (Goldstein and DeSalle 2010) path by sequencing portions of two mitochondrial genes; cytochrome oxidase I (COI, the "DNA barcode") and 16S ribosomal rDNA (16S, the most 
commonly sequenced fragment for this genus). We did this for our unknown juvenile (Genbank accession numbers JF310733-JF310734), and for a further 25 specimens of various Macrobrachium from Australia and the Indo-Pacific for 16S for comparison (accession numbers EF588319, JF310709 - JF310732). Our 16S and COI sequences were compared against all GenBank Macrobrachium sequences (109 species as of 10 December 2010) using the BLASTN search at blast.ncbi.nlm.nih.gov, and the COI sequence compared against both GenBank and the Barcoding of Life (BOLD) online database at www.barcodinglife.org (53 Macrobrachium species on the same date).

The sequences from our juvenile did not match anything closely with either gene in either database, nor against our own new sequences. BLAST searches of GenBank did not highlight any sequences with a high genetic similarity (>95\%); 16S: 88-89\% similar to many species, e.g. M. equidens, M. idae (Heller), M. novaehollandiae, and others; COI: 84-89\% M. asperulum (Von Martens), M. idae, and others. The BOLD database also did not have a similar COI sequence, with the highest matches being $85-86 \%$ for $M$. asperulum and M. lanatum Cai \& $\mathrm{Ng}$.

This result could potentially mean that this is an undescribed Australian species, or perhaps a new record of an IndoPacific species in Australia. It could even be a recent introduction from elsewhere, for example M. nipponense has become a common aquatic invader (Salman et al. 2006). The genus Macrobrachium is speciose and diverse, with approximately 240 species, and the rate of new descriptions still increasing (De Grave et al. 2008). Therefore the "only" 109 species on GenBank (a fairly large number of species for a Genbank genus) is woefully inadequate for a molecular identification as complete taxon sampling is required to have any hope of a "good" identification (Goldstein and DeSalle 2010). A complete sampling of Macrobrachium for molecules and morphology may happen one day, but it would be a huge and expensive project.

Morphology was also unable to definitively identify this specimen, largely because of an almost exclusive focus on adult male morphology within Macrobrachium taxonomy (sex bias in descriptions is a common problem, Cook et al. 2010). Holthuis (1950: 205) went so far as to say "There can not be laid too much stress on the fact that it generally is next to worthless to describe new species [of Indo-Pacific Macrobrachium] after material in which no full grown male is represented". A recent Macrobrachium key restricted to Australian species (Short 2004) does not rely exclusively on males, but still just on adults. It is also possible that other taxonomists familiar with the fauna of Indonesia or Papua New Guinea may recognise our mystery specimen, particularly as most of the eight synonyms of M. equidens are based on juveniles from that area (S. De Grave, pers. comm.).

So does this mean that we need to build up our DNA database, improve our understanding of juvenile and adult morphology, or simply sample more specimens? The answer, of course, is yes to all of them, as science is an interactive and recursive process (Goldstein and DeSalle 2010). Both types of data have a myriad of weaknesses (as pointed out in most of the references at the start of this correspondence), one of which is a narrow requirement for the types of data employed (i.e. a particular gene fragment or life history stage). For Macrobrachium molecular data specifically, there is an overreliance on a single mitochondrial gene (16S in this case, COI in many other cases). The question occurs to many taxonomists as to whether a gene sequence can really define a biological species (it can't). But the same can be said of a few carefully chosen physical characters (Cook et al. 2010), particularly as gross morphological traits are likely to be under fairly heavy selection. Key morphological characters in Macrobrachium are also known to be dependent on environmental conditions (Dimmock et al. 2004), change throughout the life of a prawn (Holthuis 1950), and to be heavily dependent not just on the sex of the individual but even on its level of social dominance (Short 2004).

So where does that leave us with our unidentified juvenile? Our molecular data imply that this specimen is not part of the currently censused Australian fauna, and yet that it may be related, at least distantly, to two species that are, namely M. equidens and M. novaehollandiae. This is consistent with John Short's independent morphological identification of the juvenile specimen as similar to M. equidens. Macrobrachium equidens in the Indo-Pacific, as currently defined, is known to host cryptic taxa (Liu et al. 2007), whilst eight synonyms are currently also available, and so finding an M. equidens-like taxon in Australia should be no surprise.

Molecular data are often useful for the testing of hypotheses generated from other types of data, such as biogeography or systematics; after all, what is a hierarchical species/genus/family structure but a hypothesis? In this case, molecular and morphological data provide the hypothesis; we predict that there is an undiscovered M. equidens/M. novaehollandiae-like species out there in central/western northern Australia that falls into the Macrobrachium estuarine/ euryhaline ecological group 1 sensu Short (2004) (as do M. equidens/M. novaehollandiae). This will only be sorted out with an integrated combination of many types of data, which is as it should be, and according to some, often is (Mitchell 2011). 


\section{What next?}

How else could we have proceeded? We could have attempted to describe a new species based on a single juvenile specimen. Don't laugh, it happened frequently in the early years of taxonomic development, leading to many synonyms (Holthuis 1950). We also could have described it based solely on a DNA sequence as the Zoological codes do not proscribe this (Cook et al. 2010). A recent paper went so far as to formally, if with tongue in cheek, name ten species of butterfly from only DNA barcode sequence data (Brower 2010, "Methods: No specimens were examined", p. 486). Molecular data is still only occasionally included in species descriptions (Chakrabarty 2010), and DNA barcoding projects rarely follow through and formally describe the "species" they identify (Brower 2010), therefore most projects still use only one type of information.

So is one form of data superior, more scientific, or more intellectual? There has been much debate about the scientific rigour of DNA barcoding (Ebach and de Carvalho 2010). Identifying a specimen using DNA barcodes is most certainly not an intellectual exercise and is actually fairly dull, but so is following a morphological key through to an identification. They are both tools and as such not necessarily fascinating, merely useful. However, the making of that key (or DNA database) is an intellectual, scientific enterprise. Further, both the morphological keys and DNA databases should have been constructed with input from experts in both fields.

Are the two "schools" becoming closer (Mitchell 2011) or more distant (Mooi and Gill 2010)? It's all a matter of perspective, as to us they are both doing the same thing (biological science), just with different tools. In any case, it's actually a false dichotomy, since biology is much more than just species identifications or descriptions, whatever form of data is used. Many types of data from other branches of biology and ecology have a bearing on species delineations, such as behaviour, biochemistry, host plant, and can all be incorporated into identifications and descriptions (Cook et al. 2010). Ecology relies on taxonomy (Ebach 2011), but ecology can also help inform taxonomy, in particular with the development of ecological niche modelling. This has now even been combined with morphology and both mitochondrial and nuclear sequences into an integrative species description (Hawlitschek et al. 2011).

There certainly should be a robust debate about where research funds go (Ebach 2011), but in our minds the scientific debate is over. Morphological, molecular and ecological data should all be used to a varying degree in all projects if possible, be they species descriptions, identifications, or any of the fascinating research that flows from and relies on these activities. So if you are a "gel jockey" or a worm/bird/shrimp-obsessed taxonomist, then you should make friends with your opposite number, because you can do something useful that the other person can't, and he or she can do something useful that you can't.

\section{Acknowledgements}

D. Wilson (Aquagreen) collected the relevant specimen and B. Cook (Griffith University), R. Kroll (Cairns Ultimate Aquarium), C. Pöllabauer (ERBIO), R. Smith (Hydrobiology), P. Unmack (NESCent) and D. Robert provided some comparative specimens. John Short (BioAccess Australia) assessed the juvenile specimen for us. We thank Chris Ashelby (Thomson Unicomarine) for reading a previous version and Sammy De Grave and Andrew Mitchell for reviewing and improving this manuscript. Funding was provided by the Australian Rivers Institute, Griffith University.

\section{References}

Brower, A.V.Z. (2010) Alleviating the taxonomic impediment of DNA barcoding and setting a bad precedent: names for ten species of Astraptes fulgerator (Lepidoptera: Hesperiidae: Eudaminae) with DNA-based diagnoses. Systematics and Biodiversity, 8, 485-491.

Chakrabarty, P. (2010) Genetypes: a concept to help integrate molecular phylogenetics and taxonomy. Zootaxa, 2632, $67-68$.

Cook, L.G., Edwards, R.D., Crisp, M.D. \& Hardy, N.B. (2010) Need morphology always be required for new species descriptions? Invertebrate Systematics, 24, 322-326.

Costa, F.O., deWaard, J.R., Boutillier, J., Ratnasingham, S., Dooh, R.T., Hajibabaei, M. \& Hebert, P.D. (2007) Biological identifications through DNA barcodes: the case of Crustacea. Canadian Journal of Fisheries and Aquatic Sciences, $64,272-295$.

Dayrat, B. (2005) Towards integrative taxonomy. Biological Journal of the Linnean Society, 85, 407-415.

De Grave, S., Cai, Y. \& Anker, A. (2008) Global diversity of shrimps (Crustacea: Decapoda: Caridea) in freshwater. 
Hydrobiologia, 595, 287-293.

Dimmock, A., Williamson, L. \& Mather, P.B. (2004) The influence of environment on the morphology of Macrobrachium australiense (Decapoda: Palaemonidae). Aquaculture International, 12, 435-456.

Ebach, M.C. (2011) Taxonomy and the DNA Barcoding Enterprise. Zootaxa, 2742, 67-68.

Ebach, M.C. \& de Carvalho, M.R. (2010) Anti-intellectualism in the DNA Barcoding Enterprise. Zoologia, 27, 165178.

Goldstein, P.Z. \& DeSalle, R. (2010) Integrating DNA barcode data and taxonomic practice: Determination, discovery, and description. Bioessays, 33, 135-147.

Hawlitschek, O., Porch, N., Hendrich, L. \& Balke, M. (2011) Ecological Niche Modelling and nDNA Sequencing Support a New, Morphologically Cryptic Beetle Species Unveiled by DNA Barcoding. PLoS ONE, 6, e16662.

Holthuis, L.B. (1950) The Decapoda of the Siboga Expedition. Part X. The Palaemonidae collected by the Siboga and Snellius Expeditions with remarks on other species. I. Subfamily Palaemoninae. Siboga Expéditie, 39, 1-268.

Hołyński, R.B. (2010) Taxonomy and the Mediocrity of DNA Barcoding - some Remarks on Packer et al. 2009: DNA Barcoding and the Mediocrity of Morphology. Arthropod Systematics and Phylogeny, 68, 143 - 150.

Liu, M.Y., Cai, Y. \& Tzeng, C.S. (2007) Molecular systematics of the freshwater prawn genus Macrobrachium Bate, 1868 (Crustacea: Decapoda: Palaemonidae) from mtDNA sequences, with emphasis on East Asian species. Zoological Studies, 46, 272-289.

Mitchell, A. (2011) DNA barcoding is useful for taxonomy: a reply to Ebach. Zootaxa, 67-68.

Mooi, R.D. \& Gill, A.C. (2010) Phylogenies without Synapomorphies-A Crisis in Fish Systematics: Time to Show Some Character. Zootaxa, 2450, 26-40.

Murphy, N.P. \& Austin, C.M. (2004) Multiple origins of the endemic Australian Macrobrachium (Decapoda: Palaemonidae) based on 16S rRNA mitochondrial sequences. Australian Journal of Zoology, 52, 549-559.

Packer, L., Gibbs, J., Sheffield, C. \& Hanner, R. (2009) DNA barcoding and the mediocrity of morphology. Molecular Ecology Resources, 9, 42-50.

Salman, S.D., Page, T.J., Naser, M.D. \& Yasser, A.a.G. (2006) The invasion of Macrobrachium nipponense (de Haan, 1849) (Caridea: Palaemonidae) into the Southern Iraqi Marshes. Aquatic Invasions, 1, 109-115.

Short, J.W. (2004) A revision of Australian river prawns, Macrobrachium (Crustacea: Decapoda: Palaemonidae). Hydrobiologia, 525, 1-100.

Stevens, M.I., Porco, D., D'Haese, C.A. \& Deharveng, L. (2011) Comment on "Taxonomy and the DNA Barcoding Enterprise" by Ebach (2011). Zootaxa, 2838, 85-88.

Valdecasas, A.G., Williams, D. \& Wheeler, Q.D. (2008) 'Integrative taxonomy' then and now: a response to Dayrat (2005). Biological Journal of the Linnean Society, 93, 211-216. 